\title{
A STUDY OF NUTRITION AND THE NUTRITIONAL STATUS OF SERVICEMEN, ASSESSED ON THE BASIS OF ANTHROPOMETRIC INDICATORS
}

\author{
Pavlin Ivanov GLUSHKOV \\ "Vasil Levski" National Military University, Veliko Tarnovo, Bulgaria \\ pavlin_glushkov@mail.bg
}

\begin{abstract}
The modern food industry has the potential to produce and offers "unlimited" quantities of all sorts tempting foods in response to the expectations of consumers. The development of powerful marketing and promotional campaigns in pursuance of the objective to boost sales creates the perfect conditions for the modification of the eating patterns of the population. In addition, this makes it possible for foods, whose everyday use would increase the risk of non-communicable diseases, to permanently find their place on the menu in every household.
\end{abstract}

Keywords: overweight, foods, nutrient, status, energy

\section{Introduction}

In recent years, we have witnessed a considerable change in the morbidity of the population, including in Bulgaria, which is connected with the changes in the nutrition and life style of people. According to experts, these changes have contributed to an epidemic of non-communicable diseases such as cardio-vascular diseases (coronary disease of the heart, hypertension, stroke), some cancerous diseases, diabetes, obesity and others. According to the international ranking of the World Health Organization (WHO) over the past decades Bulgaria has maintained high mortality rates resulting from diseases of the circulatory system, and occupies one of the first places in the world as regards brain stroke mortality.

The spread of obesity has increased threefold over the last 2 decades [8].

The need to create standardised and harmonized systems for monitoring obesity both at national and European level has been acknowledged, on the basis of which policies can be developed and assessed within the European region [5].

2. A study of nutrition and the nutritional status of servicemen

The national monitoring of obesity and underweight of the population is a necessary prerequisite for the development and implementation of an adequate national food and health policy aimed at and prioritizing population groups at risk.

For the first time in history overweight and obesity are more widely spread than underweight among the world population a new model for which the WHO has coined the term "globesity". The increase in the body mass index (BMI) leads to an increase in the risk of occurrence of noncommunicable diseases such as cardiovascular diseases, diabetes, osteoarthritis, and certain types of cancer. The national studies of the nutrition and nutritional status by anthropometric indicators among different groups of the Bulgarian population for the period 1998 to 
2011, confirm the negative changes and trends observed in Europe and the US, as well as in other parts of the world. A significant increase in the incidence of overweight and obesity in all age groups and in both sexes has been recorded in Bulgaria over the past twenty years [1].

In response to this negative trend, the National Action Plan for "Food and Nutrition" sets as its main objective the need to improve the health of the Bulgarian population through the improvement of nutrition, so as to reduce the risk of diseases associated with food and eating habits. One of the activities that needs to be implemented in order to accomplish the above-stated objective is the provision of an adequate and healthy diet to special population groups that are exposed to specific physical and psychological stresses, one such group being the armed forces. Here we need to highlight the implementation of the following subactivities assigned by the Ministry of Defence and the Military Medical Academy, targeting the soldiers in the armed forces: studying the nutrition and nutritional status of the soldiers, assessed on the basis of anthropometric indicators; development of practical recommendations for adequate and healthy nutrition of soldiers; ensuring the monitoring of the nutrition and nutritional status of soldiers. Directly connected with the results from the study of the nutritional status of the soldiers is the organization of the provision of food in the Bulgarian Army. The development of adequate nutritional standards is the basis for the provision of outsourcing services in the Bulgarian Army, as well as for cutting down on expenditures from the formations. [10]

The analysed literature indicates that outsourcing within the armed forces means the use of the management capacity of the private sector for carrying out similar activities by the staff of the armed forces or civilian staff. The application of outsourcing can be found both in peacetime activities of the Bulgarian Army, and during participation in dispatch, humanitarian and other operations in response to crises outside the territory of the Republic of Bulgaria [11].

In connection with the above mentioned, for the period from 14 December 2015 to 26 April 2016, a study of the nutritional status of the soldiers in the Armed Forces of the Republic of Bulgaria was carried out. The study was carried out among soldiers who arrived at NMU "Vasil Levski" for preparation for participation in the mission in Afghanistan, servicemen receiving their education at the Professional Sergeant College of NMU "Vasil Levski", military personnel at the Military Academy "G. S. Rakovski", servicemen from NMU "Vasil Levski", and servicemen from several military formations, as well as from The Crisis Management and Disaster Response Center of Excellence - town of Sofia.

A questionnaire was drawn up for this purpose, including 71 questions related to personal information about: their status in the army, physical and health data, food preferences and eating habits, use of alcohol and cigarettes, physical activity, drinking of water and liquids, funds set aside for food, etc. The participants in the study were randomly selected and have remained anonymous. Each one of them has voluntarily completed the questionnaire.

A total of 37 people, 33 men and 4 women were involved in the survey. They serve in 12 different military formations. The experience of the various servicemen in peace-keeping operations (PKO) covers the period from 2003 to 2015 in Iraq, Afghanistan, Kosovo and Bosnia and Herzegovina. The total of the missions in which the respondents had been involved were 77, with one soldier involved respectively in 5 and 4 missions, nine people involved in 3 missions, fifteen people in 2 and eleven people in 1 mission. The distribution of servicemen by categories was as follows: 11 officers, of which 2 women; 20 non-commissioned officers, of which 1 woman, and 6 soldiers, 
of which one woman. The age of the participants is between 27-47 years for men and 34-39 for women, with the majority ( 25 people) falling into the $37-41$ years age group.

In the assessment of the nutritional status the following generally accepted indicators were included [6]: information about the gaining or loss of weight, pace of the changes in weight, changes in appetite, past diseases, defining energy intake, reduced or increased food intake in comparison with a preceding period, physical activity, current health status, intake of liquids.

The study uses the anthropometric method in the assessment of the nutritional status of the servicemen. It measures the anatomical indicators related to: sex, body weight, height, body mass index (BMI), waist measurement, forearm measurement, and triceps skin-fold thickness. BMI is a medico - biological indicator which serves to determine the normal healthy weight in people with a different hight and to diagnose obesity and malnutrition .

The results on the physical condition of the respondent servicemen involved in dispatch operations on the basis of the measured BMI are shown in Table 1.

Table 1 Physical condition of the respondent men and women involved in PKO by BMI

\begin{tabular}{|c|c|c|c|c|c|c|}
\hline \multirow{2}{*}{ № } & \multirow{2}{*}{$\begin{array}{c}\text { Assessment } \\
\text { of the BMI }\end{array}$} & \multirow{2}{*}{$\begin{array}{c}\text { BMI (kg/m } \\
\text { 2) }\end{array}$} & $\begin{array}{c}\text { Men - 33 people } \\
\text { Absolute } \\
\text { number }\end{array}$ & $\begin{array}{c}\text { \% of all the } \\
\text { respondents }\end{array}$ & $\begin{array}{c}\text { Absolute } \\
\text { number }\end{array}$ & $\begin{array}{c}\text { Wof all the } \\
\text { respondents }\end{array}$ \\
\hline 1. & Underweight & $<18.5$ & - & - & - & - \\
\hline 2. & $\begin{array}{c}\text { Normal } \\
\text { weight }\end{array}$ & $18.50-24.90$ & 6 & $18 \%$ & 4 & $100 \%$ \\
\hline 3. & Overweight & $25.00-29.90$ & 21 & $64 \%$ & - & - \\
\hline 4. & $\begin{array}{c}\text { Obesity I } \\
\text { degree }\end{array}$ & $30.00-34.90$ & 5 & $15 \%$ & - & - \\
\hline 5. & $\begin{array}{c}\text { Obesity II } \\
\text { degree }\end{array}$ & $35.00-39.90$ & - & - & - & - \\
\hline 6. & $\begin{array}{c}\text { Obesity III } \\
\text { degree }\end{array}$ & $\geq 40.00$ & - & - & - & - \\
\hline 7. & No response & & 1 & $3 \%$ & - & - \\
\hline
\end{tabular}

According to some Bulgarian scientists [3] over the past decades the incidence of overweight and obesity cases has almost doubled in developed countries. In Europe around $50 \%$ of the population between the ages of 35 and 65 are exposed to this risk factor for their health. In England 15\% of men and $18 \%$ of women in the 16-64 age group suffer from obesity. In the United States $-39 \%$ of men and $25 \%$ of women are overweight and $20 \%$ and $25 \%$ respectively suffer from obesity. In Bulgaria this problem is also on the agenda. The incidence of overweight for the different age groups over 30 years reaches $30-44 \%$ and in the case of obesity $-17 \%$. The results from the survey of the servicemen involved in PKO show that the risk of noncommunicable diseases is low in $100 \%$ of women and in $18 \%$ of men. In $64 \%$ of men the risk of diseases is high and in $15 \%$ of them it is moderately high. According to the National recommendations for healthy eating for the population of Bulgaria, obesity creates psycho-social problems. The classification of the weight of the respondents is carried out on the basis of the body mass index and the associated health risk according to the World Health Organization and the National Centre of Public Health Protection. In determining another indicator which can be used to 
predict the risk of diseases, such as the relative body fat percentage (BFP, [\%]), anthropometric formulae have been used on the basis of the size of the body, height and weight in particular. The method of calipometry is not used because it is physically impossible to procure an instrument for each participant and to train each one of them how the readings are taken.

For men between 24-68 years with relatively high body fat percentage the formula looks as follows [7]:

$$
\begin{aligned}
& \% \mathrm{BFP}=0,31457 * \mathrm{WM}-0,10969 * \mathrm{BM} \\
& +10,834
\end{aligned}
$$

Where $\mathrm{WM}=$ waist measurement $(\mathrm{cm})$ and $\mathrm{BM}=$ body mass $(\mathrm{kg})$.

For women between 20-60 years with relatively high body fat percentage the formula looks as follows [7]:

$$
\% \mathrm{BFP}=0,11077 * \mathrm{WM}-0,17666 * \mathrm{BH}+
$$$$
0,14354 * \mathrm{BM}+10,834+51,033
$$

Where $\mathrm{WM}=$ waist measurement $(\mathrm{cm}), \mathrm{BH}$ $=$ body height and $\mathrm{BM}=$ body mass $(\mathrm{kg})$.

The standard error according to Russian scientists [7] in determining the BFP\% in these formulae is from $3 \%$ to $3.6 \%$.

According to the classification of [7] the relative body fat percentage for the general population (very low, low, optimal, moderate and high) of men and women, the following status of the respondents in the survey can be established:

1. Men: 26 People provide the necessary data for the calculation and the other 7 people do not provide the necessary data. All $100 \%$ of the respondents who provided data have a high relative body fat percentage.

2. Women: 3 people provide the necessary data for the calculation and 1 person does not provide the necessary data. All $100 \%$ of the respondents who provided data have a high relative body fat percentage.

The high values of the waist measurements are associated with higher risk for the individual to get diabetes, hypertension and cardiovascular diseases. If the waist measurement in men is above $102 \mathrm{~cm}$ and in women above $92 \mathrm{~cm}$, this indicates a significantly higher health risk (myocardial infarction, stroke). According to certain sources [9], the increase in the waist measurement leads to an increase in blood pressure. In this connection, we present the data of the servicemen involved in the survey compared with the classification of the WHO: 7 of the men $(27 \%$ of all who submitted data) have low health risk, 15 people $(58 \%$ of all who submitted data) have a high health risk and 4 people (15\% of all who submitted data) have a considerably high health risk. 7 men did not provide data. 3 of the women $(100 \%$ of all who submitted data) have low health risk, and 1 woman did not provide data.

On the surface, malnutrition or undernourishment is one remote aspect of nutrition in the Ministry of Defence, but according to specialized studies [2], it can cause death, disability, discomfort and serious increases in the cost of social care for people and society. It is believed that malnutrition is widespread and affects all ages - both patients in the hospitals and a great number of the elderly. The risk level shall be calculated in relation to the assessment of the nutritional status.

According to the ESPEN recommendations (The European Society for Clinical Nutrition and Metabolism) for universal nutritive screening test (for malnutrition) for adults, in respect of weight loss within 3-6- months, a loss of weight $\leq 5 \%$ is graded as 0 , a loss of weight $=5-10 \%$ is graded as 1 and a loss $\geq 10 \%$ is graded as 2 . In addition to the weight, in assessing the nutritive risk, the BMI is also taken into account, as well as the effects of acute diseases (lack of food intake or reduced food intake for more than 5 days). In our study these two indicators should be ignored as there is no data for any of the respondents to be underweight $(\mathrm{BMI}<18.5)$ and all perform their duties in the armed forces, i.e. they are healthy. The results of the survey show that only one woman lost $5-10 \%$ of her weight over the past 3-6 months. This condition, according to the nutritive screening of ESPEN, shall be 
graded as1. The risk of malnutrition is determined as moderate (there are three levels of risk - none, moderate and high). On the basis of all respondents, $2.7 \%$ fall within this category of risk and in the case of women the result indicates $25 \%$ of them. In this case a second screening is recommended at population level $<1$ to $>$ 6 months and if necessary food recommendations should be given. It should be noted at this point that $33 \%$ of the men and $50 \%$ of the women lose weight when they are on a mission.

\section{Conclusions}

By determining the nutritional status an opportunity is provided to determine the eating disorders and nutritional imbalances. They in turn can be used as a basis to make a possible connection with certain diseases, established in specialized examinations among servicemen, as well as to make a more generalized assessment and to provide guidance and recommendations for overcoming the disparities.

On the basis of the results obtained in the conducted survey, the assessment of the nutritional status and the way of life of the participants in the PKO can be defined as unhealthy. This is the strongest argument for undertaking steps to remove one strong impact factor, namely the inadequate nutrition standards which are currently applied in the Ministry of Defence. In this connection, it is necessary to develop a new set of food products and new nutrition standards for this category of servicemen.

The definition of scientifically substantiated energy needs for people is of crucial importance for the control and prevention of malnutrition, but also for facilitating the cutting down on excessive intake of energy through food [4].

\section{References}

[1] Birdanova V., Petkov A., Stoynovska M., Petkov K., Statev N., A study of anthropometric indicators for the assessment of the nutritional status of students in medical specialities. Nauka Dietetics, 1-2/2013.

[2] Enteral feeding. Journal, 1/2015.

[3] Manolova A., Tsolova G., Grigorova-Petrova K., Dimitrov P., Petrova S., Medical facts relating to physical activity. Project BG051PO001-5.3.03-0001-C0001.

[4] Nichev N., Gloushkov P., Economic efficiency of the feeding of servicemen and civilians in NMU "Vasil Levski", under preparation for participation in dispatch operations. Sofia: Publishing complex of the University of National and World Economy - reports from the tenth International Scientific Conference on the topic of Logistics in a changing world, dedicated to the $25^{\text {th }}$ anniversary of the speciality of Business logistics at the UNWE. 329-339, IXBN 978-954-644-900-9, 2016.

[5] Petrova S., Duleva V., Rangelova L., Dimitrov P., Baikova D., Konstantinova M., Monitoring of the nutritional status of the Bulgarian population. Distribution and trends in obesity and underweight. Nauka Dietetics, 2/2012.

[6] Popova, D. Assessment of the nutritional status. Nauka Dietetics, 2/2009.

[7] Martirosov E., Nikolaev D., Rudnev S., Technologies and Methods for defining the composition of the human body. Moscow: Nauka, 2006.

[8] World Health Organization. European Ministerial Conference on Counteracting Obesity: Conference Report. Copenhagen: WHO, ISBN 978928907281 6, 2007.

[9] http://www.rzi-starazagora.org

[10] Dimitrova S., Nichev, N., Stefanov, N. Development of Outsourcing Services. International conference Knowledge-Based Organization. Volume 21, issue 1 Pages 192-197, 2015.

[11] Dimitrova, S., Nichev, N., Analysis of modern humanitarian operations concepts and participation of military units in them, Revista Academiei Fortelor Terestre, Vol. XVI, Nr. 4 (64) Trimestrul IV, pp.348-355, 2011. 